\title{
Screening of selected ethnomedicinal plants from South Africa for larvicidal activity against the mosquito Anopheles arabiensis
}

\author{
Rajendra Maharaj ${ }^{1 *}$, Vinesh Maharaj ${ }^{2}$, Neil R Crouch ${ }^{3}$, Niresh Bhagwandin ${ }^{4}$, Peter I Folb ${ }^{4}$, Pamisha Pillay ${ }^{2}$ and
} Reshma Gayaram

\begin{abstract}
Background: This study was initiated to establish whether any South African ethnomedicinal plants (indigenous or exotic), that have been reported to be used traditionally to repel or kill mosquitoes, exhibit effective mosquito larvicidal properties.

Methods: Extracts of a selection of plant taxa sourced in South Africa were tested for larvicidal properties in an applicable assay. Thirty $3^{\text {rd }}$ instar Anopheles arabiensis larvae were exposed to various extract types (dichloromethane, dichloromethane/methanol) (1:1), methanol and purified water) of each species investigated. Mortality was evaluated relative to the positive control Temephos (Mostop; Agrivo), an effective emulsifiable concentrate larvicide.
\end{abstract}

Results: Preliminary screening of crude extracts revealed substantial variation in toxicity with 24 of the 381 samples displaying 100\% larval mortality within the seven day exposure period. Four of the high activity plants were selected and subjected to bioassay guided fractionation. The results of the testing of the fractions generated identified one fraction of the plant, Toddalia asiatica as being very potent against the An. arabiensis larvae.

Conclusion: The present study has successfully identified a plant with superior larvicidal activity at both the crude and semi pure fractions generated through bio-assay guided fractionation. These results have initiated further research into isolating the active compound and developing a malaria vector control tool.

\section{Background}

Malaria remains one of the highest priority insect transmitted diseases around the world, with Africa carrying the greatest burden. The Anopheles arabiensis mosquito is considered one of the major vectors of malaria in southern Africa with Anopheles funestus the next most important [1].

Within South Africa, malaria affects five million people in the low and high risk areas of the country [2] with the threat concentrated in Mpumalanga, Limpopo and (north-eastern) KwaZulu Natal provinces [3]. According to the strategic plan for communicable diseases in South Africa, one of the main objectives is

\footnotetext{
* Correspondence: rmaharaj@mrc.ac.za

'South African Medical Research Council, 491 Ridge Road, Overport, Durban 4001, South Africa

Full list of author information is available at the end of the article
}

addressing malaria, to reduce the incidence of local transmission from 0.7 to 0.56 cases per thousand. Strategies employed include indoor spraying, definitive diagnosis of malaria cases and effective case management [4]. The malaria control strategy in South Africa has a two-pronged approach, targeting the malaria parasite with anti-malarial drugs and controlling the vector through the use of insecticides, targeting both larval and adult life stages [5].

Historically, the use of synthetic insecticides has been very effective in reducing malaria transmission. However, over time success has been hampered by the development of insecticide resistance in mosquitoes. Resistance to pyrethroids [6] and DDT [7] has been reported, and the potential for carbamate resistance has been detected in An. arabiensis, in northern KwazuluNatal [8]. 
The effective alternative insecticides that are currently available are up to six times more expensive than those (DDT and pyrethroids) used previously in regional malaria control programmes and accordingly are not cost effective for indoor residual spraying [9].

As most mosquito breeding sites are temporary habitats, the use of larvicides by malaria control programmes has been very limited. Larvicidal applications have however been favoured mainly in tourist destinations to limit mosquito populations. This form of vector control has been used as a complementary strategy to indoor residual spraying (for adult stages) and has been suggested as a method for eliminating over-wintering larval populations [10,11].

Since insecticide resistance threatens to contribute towards the reintroduction of malaria in many parts of South Africa, efforts have focussed on finding an alternative form of mosquito control. For new interventions to be integrated into most malaria control programmes, they should necessarily be cost effective, practical and accessible.

The concept of screening plant extracts for larvicidal activity is not new. The insecticide pyrethroid was derived from flowers of the asteraceous Tanacetum cinerariifolium (= Chrysanthemum cinerariifolium, the Dalmatian chrysanthemum or pyrethrum daisy) [12]. Production of such constituents has been interpreted as a means by which plants protect themselves from harmful insect herbivores. The notion of using such plant extracts to control mosquito larvae has received widespread research attention, with plants from various countries tested for larvicidal activity [13-16]. Such plant extracts have been investigated for their ability to kill a number of mosquito species known to be malaria vectors [14,17-19].

The efficacy of different plant parts has been well established [16,20,21]. The flower [22], leaf and seed [21], fruits and roots [23,24] have all been investigated for their larvicidal properties, revealing variably useful leads for the development of practical interventions.

Although a small number of studies have investigated larvicidal activity of plant extracts against Anopheles stephensi $[25,26]$ there are limited data regarding the testing of plant extracts against An. arabiensis. Zarroug et al. [27] tested some Sudanese plant extracts against An. arabiensis larvae and obtained significant mortality in second and fourth instar larvae when using water extracts of Balanites aegyptiaca.

In the present study, 381 crude plant extracts were investigated for their larvicidal effect on An. arabiensis, and plants exhibiting promising results during screening were selected for further phytochemical investigation. The extracts consisted of plants found native or naturalized in southern Africa.

\section{Methods}

\section{Selection and collection of plant material}

A survey of relevant published literature on ethnomedicinal plants used in East and southern Africa revealed that a number of taxa have been reported to be used as mosquito repellents, or to repel or kill other invertebrates. However, given the limited quantity of documented data available, it was decided to not make a distinction between insect repellents and insecticides (both larva- and adulticides), but rather to consider a pool of plants with anti-insect activity.

In order to select the most relevant taxa for screening, all were ranked following the application of weighted criteria, principally ethnobotanical and chemotaxonomic (including such elements as popularity in ethnomedicinal trade, reports on insecticidal and/or mosquitocidal application, reports on insect and/or mosquito repellent application, and the known presence and diversity of repellent/insecticidal constituents in the family to which it belongs). Higher weighting was provided to plants indigenous to the Flora of Southern Africa region (FSA). A similar semi-quantitative selection method has previously been applied to identify and rank both antiplasmodial [28], mosquito repellent [29] and adulticidal plant [30] candidates from South Africa. From the ranked list selected plants were collected throughout South Africa. Different plant parts, namely, leaves, roots, stems, fruits, flowers, seeds, twigs and bark, and combinations of the above were sourced to generate extracts. In some instances, extracts were made of the whole plant. The plant organ(s) selected for extract preparation were based largely on availability at the time of collection.

The identity of plant material was determined at the National Herbarium of South Africa (PRE) where voucher specimens (cited in Additional file 1: Table S1) have been lodged.

\section{Extract preparation}

Plant samples were separated into different components and dried in an oven at $30-60^{\circ} \mathrm{C}$. The drying time and temperature varied depending on the nature of the plant part. Dried plant material was ground to a coarse powder using a hammer mill and stored at ambient temperature prior to extraction. For each extraction procedure, 100-500 g of powdered plant material was sequentially extracted, with cold dichloromethane (DCM), $\mathrm{DCM} /$ methanol (MeOH) (1:1), $\mathrm{MeOH}$ (CP Grade; Merck) and purified water. Organic extracts were concentrated by rotary vacuum evaporation below $45^{\circ} \mathrm{C}$ and then further dried in vacuo at ambient temperature for $24 \mathrm{~h}$. The aqueous extracts were concentrated by freezedrying. All dried extracts were stored at $-20^{\circ} \mathrm{C}$. 
Crude plant samples were dissolved in either acetone (AR Grade; Merck) or distilled water depending on their initial extraction procedure, thus forming a $10 \mathrm{mg} / \mathrm{ml} \mathrm{so-}$ lution. Dichloromethane and dichloromethane/methanol extracts were reconstituted in acetone whereas aqueous extracts were made up using distilled water.

\section{Larvicidal screening}

A $1 \mathrm{ml}$ volume of the extract stock solution was added to a vessel containing thirty $3^{\text {rd }}$ instar mosquito larvae in 0.25 litres of distilled water, producing a final concentration of $40 \mathrm{mg} / \mathrm{l}$. The target species had been a colonized strain of An. arabiensis from Zimbabwe, which had been reared according to the World Health Organization's [31] guidelines in an insectary simulating the temperature, humidity and lighting of a malaria endemic environment. The negative control trials included either acetone or distilled water, whilst the positive control temephos (Mostop; Agrivo), an effective larvicide was tested at a concentration of $0.2 \mathrm{mg} / \mathrm{l}$.
Each container was monitored for larval mortality at 24-hour intervals for a period of seven days and fed at regular intervals. The percentage mortality was calculated relative to the negative control.

\section{Results and discussion}

A total of 80 taxa from 42 families of plants native to or naturalized in southern Africa have been screened for activity against the $3^{\text {rd }}$ instar larvae of An. arabiensis. The third stage of larvae had been used to determine if the extracts had induced any growth inhibition or abnormalities in ecdysis to $4^{\text {th }}$ instar and pupation. Significant events had included failed or delayed transition relative to negative control. The results of primary screening have been presented alphabetically by family, genus and species and thereafter in descending order of mortality over a period of seven days (Cited in Additional file 1: Table S1). In order to assess the biological activity of each extract, all samples were subjected to stringent criteria to identify plants that exhibited larvicidal

Table 1 Crude extracts exhibiting $100 \%$ mortality during preliminary laboratory trials

\begin{tabular}{|c|c|c|c|c|c|}
\hline Family & Plant species & $\begin{array}{l}\text { Voucher } \\
\text { number }\end{array}$ & Plant part & Extraction & $\begin{array}{l}\text { Mortality } \\
\text { time (hours) }\end{array}$ \\
\hline Araliaceae & Cussonia spicata Thunb. & EN00867 & Fruit & DCM & 72 \\
\hline Asphodeleace & $\begin{array}{l}\text { Aloe greatheadii Schönland } \\
\text { var. davyana (Schönland) Glen \& D.S.Hardy }\end{array}$ & EN00021 & Leaves and twigs & DCM & 120 \\
\hline \multirow[t]{4}{*}{ Asteraceae } & Litogyne gariepina (DC.) Anderb. & EN00213 & Roots & DCM & 96 \\
\hline & Pentzia globosa Less. & EN00506 & Leaves & Water & 48 \\
\hline & Psiadia punctulata (DC.) Oliv. \& Hiern ex Vatke & BP00278 & Leaves & DCM & 144 \\
\hline & Vernonia natalensis Oliv. \& Hiern & EN00331 & Whole plant & Water & 48 \\
\hline \multirow[t]{2}{*}{ Capparaceae } & Capparis tomentosa Lam. & EN00222 & Stems & Water & 24 \\
\hline & Capparis tomentosa Lam. & EN00222 & Leaves & Water & 48 \\
\hline \multirow[t]{2}{*}{ Ebenaceae } & Euclea natalensis A.DC. & EN00760 & Roots & DCM & 48 \\
\hline & Euclea natalensis A.DC. & EN00760 & Stems & DCM & 96 \\
\hline Euphorbiaceae & *Ricinus communis $\mathrm{L}$. & EN00768 & Fruit & DCM & 48 \\
\hline \multirow[t]{3}{*}{ Fabaceae } & Philenoptera violacea (Klotzsch) Schrire & MM00019 & Stems & DCM & 24 \\
\hline & Pterocarpus angolensis DC. & EN00083 & Roots & Water & 48 \\
\hline & Pterocarpus angolensis DC. & EN00083 & Roots & $\mathrm{MeOH}$ & 144 \\
\hline Lamiaceae & *Hyptis pectinata (L.) Poit. & BP00243 & Leaves, stems and fruits & Water & 48 \\
\hline Olacaceae & Ximenia caffra Sond. var. caffra & EN00110 & Roots & Water & 48 \\
\hline Phyllanthaceae & Flueggea virosa (Roxb. ex Willd.) Voigt & BP00207 & Leaves and twigs & Water & 24 \\
\hline \multirow[t]{2}{*}{ Plumbaginaceae } & Plumbago zeylanica L. (1) & EN00208 & Leaves & DCM & 48 \\
\hline & Plumbago zeylanica L. (2) & EN00208 & Leaves & DCM & 48 \\
\hline \multirow[t]{3}{*}{ Rutaceae } & Macrostylis squarrosa Bartl. \& H.L.Wendl. & EN00758 & Stems & DCM & 24 \\
\hline & Toddalia asiatica (L.) Lam. (1) & EN00211 & Leaves & DCM & 72 \\
\hline & Toddalia asiatica (L.) Lam. (2) & EN00211 & Leaves & DCM & 72 \\
\hline Thymelaeaceae & Gnidia cuneata Meisn. & EN00716 & Stems & DCM & 144 \\
\hline Zingiberaceae & Siphonochilus aethiopicus (Schweinf.) B.L.Burtt & EN00148 & Rhizomes & Ether & 72 \\
\hline
\end{tabular}


properties. Any plant with activity of more than $80 \%$ mortality was considered significant for further investigation [32]. However, it must be borne in mind that assays were conducted primarily using the crude plant extract.

The results of preliminary screening of 381 plant extracts against the third instar larvae revealed substantial variation in toxicity, differing with plant species, organ, and extraction type. Whilst a substantial number of plants showed moderate to low toxic effects, almost $11 \%$ (24 extracts) of the total samples possessed good larvicidal properties relative to the positive control. In an earlier study, Maharaj et al. [30] screened crude extracts of many of the same plant species here reported on, for adulticidal properties. Very limited adulticidal activities were observed, indicating a much greater susceptibility of larvae to the same extracts. The toxicity of the highly active positive control sample had exhibited 100\% mortality within 24 hours of exposure, whilst both negative control tests indicated insignificant toxicity of solvents used.

Of the 42 extracts exhibiting high activity in this study, a total of 24 samples demonstrated excellent results (100\% mortality during the seven day exposure period) (Table 1). In a separate study, the crude extracts used in this experiment were screened and five samples with repellent properties identified during preliminary assays [29]. Although none of the potential repellents had maintained a repellent effect over a prolonged period, one of five samples, Litogyne gariepina had also been identified as a potential larvicide in the current study, suggesting a dual effect in different environments.

Results indicated that organic extracts exhibit a greater effect than aqueous extracts, a trend also noted in the previous repellency study [29]. In another similar insecticidal experiment, two of the highly active families screened during this experiment, Rutaceae and Zingiberaceae, were reported to yield promising botanical larvicides [33]. It was also observed in this study that almost half of the prioritized extracts induced mortality within 48 hours, suggesting a very high toxic effect at the crude stage.

Based on the mortality obtained from a large number of crude extracts, the biological activity of each plant was assessed. The most promising candidates represented by four taxa and four extracts were subjected to bioassay-guided fractionation. A total of 36 semi pure fractions were tested in a manner similar to that of the crude extracts (Table 2). A loss of activity was observed in two of the four extracts, relative to the preliminary screening of crude samples. Aloe greatheadii var. davyana (Asphodelaceae) showed 100\% mortality for only one fraction, whilst four of the five fractions of Toddalia asiatica (Rutaceae) induced 100\% mortality
Table 2 The larvicidal activity of thirty six fractions of the most promising plant extracts

\begin{tabular}{|c|c|c|c|c|c|}
\hline $\begin{array}{l}\text { Plant } \\
\text { species }\end{array}$ & Family & $\begin{array}{l}\text { Plant } \\
\text { part }\end{array}$ & Extraction & $\begin{array}{l}\text { Fraction } \\
\text { Number }\end{array}$ & $\begin{array}{c}\% \\
\text { Mortality }\end{array}$ \\
\hline \multirow[t]{8}{*}{ Rutaceae } & $\begin{array}{l}\text { Macrostylis } \\
\text { squarrosa }\end{array}$ & Stems & DCM & $1-7$ & 22 \\
\hline & & & & $11-14$ & 70 \\
\hline & & & & $19-21$ & 68 \\
\hline & & & & 22 & 25 \\
\hline & & & & 23 & 5 \\
\hline & & & & 24 & 18 \\
\hline & & & & $26-29$ & 57 \\
\hline & & & & $44-63 / 17-20$ & 77 \\
\hline \multirow[t]{5}{*}{ Rutaceae } & $\begin{array}{l}\text { Toddalia } \\
\text { asiatica }\end{array}$ & leaves & DCM & $2-3$ & 10 \\
\hline & & & & $100-122$ & 100 \\
\hline & & & & $17-27 / 36-60$ & 100 \\
\hline & & & & $36-47 / 8-12$ & 100 \\
\hline & & & & 168-180/11-19 & 100 \\
\hline \multirow[t]{12}{*}{ Asphodeleace } & $\begin{array}{l}\text { Aloe } \\
\text { greatheadii } \\
\text { var. } \\
\text { davyana }\end{array}$ & $\begin{array}{l}\text { Leaves + } \\
\text { Twigs }\end{array}$ & DCM & $1-11$ & 18 \\
\hline & & & & $12-18$ & 43 \\
\hline & & & & $19-27$ & 23 \\
\hline & & & & $28-32$ & 32 \\
\hline & & & & $33-41$ & 100 \\
\hline & & & & $42-52$ & 20 \\
\hline & & & & $53-54$ & 17 \\
\hline & & & & $55-67$ & 58 \\
\hline & & & & $68-75$ & 42 \\
\hline & & & & $76-77$ & 63 \\
\hline & & & & $78-82$ & 25 \\
\hline & & & & $83-85$ & 12 \\
\hline \multirow[t]{11}{*}{ Asteraceae } & $\begin{array}{l}\text { Vernonia } \\
\text { natalensis }\end{array}$ & All parts & Water & $31-35$ & 27 \\
\hline & & & & $36-38$ & 10 \\
\hline & & & & $29-30$ & 22 \\
\hline & & & & $1-28$ & 20 \\
\hline & & & & $39-41$ & 32 \\
\hline & & & & $42-44$ & 40 \\
\hline & & & & $45-50$ & 28 \\
\hline & & & & $51-54$ & 12 \\
\hline & & & & $55-65$ & 50 \\
\hline & & & & $66-69$ & 57 \\
\hline & & & & $70-76$ & 45 \\
\hline
\end{tabular}


within 96 hours of exposure, making it the favoured extract for further investigation of active compounds. The Rutaceace have earlier been shown to induce insecticidal effects against mosquitoes [34,35]. Murraya koenigii possesses mosquitocidal properties through effects of hormone regulation with subsequent disruption of instar development of Anopheles stephensi, Culex quinquefasciatus and Aedes aegypti [34]. Tiwari et al. [35] found that the essential oil obtained from seeds of Zanthoxylum armatum (Rutaceae) displayed promising larvicidal activity when tested against An. stephensi, Cx quinquefasciatus and Ae. aegypti larvae.

Toddalia asiatica has gained popularity amongst traditional health practitioners for treating numerous ailments. Amongst the documented ethnomedicinal uses, the fruit of this plant is known to have been popularly applied in treating malaria, particularly in East Africa [36]. The current study has revealed that the leaves of $T$. asiatica contain compounds toxic against the larvae of $A n$. arabiensis. The current findings compare well with a study conducted in India, which has revealed that T. asiatica fruits contains anti-larval compounds active against the $3^{\text {rd }}$ instar stages of the two mosquito vectors, Ae. aegypti and Cx quinquefasciatus [37].

\section{Conclusions}

Although organophosphates, such as temephos, have shown to be very effective in this study, they are not favoured due to their high toxicity to humans, low stability and high cost implications [38]. Bioactive constituents of plants hold potential to be employed as larvicides useful in controlling mosquito vectors [39]. The present study has successfully identified a plant with superior larvicidal activity for both the crude and semi pure fractions thus indicating a potential for use in the control of the malaria vector, $A n$. arabiensis. Results obtained during this study have initiated ongoing investigations into the isolation of purified active components of $T$. asiatica, with a view to developing an environmentally acceptable tool of value in integrated vector control.

\section{Additional file}

Additional file 1: Table S1. Mosquito larvicidal screening results of extracts from South African ethnomedicinal plants.

\section{Competing interests}

There have been no competing interests.

\section{Authors' contributions}

RM was involved in designing of the study and supervising trials. RG conducted the experiments and was involved in the interpretation of the results. NRC was involved in rationally selecting suitable plant candidates fo investigation. Extracts were prepared by VM and PP. NB and PF coordinated and provided scientific inputs into the entire study. All authors read and approved the final manuscript.

\section{Acknowledgements}

We gratefully acknowledge the Department of Science and Technology of South Africa for the Innovation Fund Grant (Project 31313 and TM1002FP) Furthermore, we wish to thank Mr Ashokoomar Saikoolal for his technical assistance in conducting the larvicidal screening.

\section{Author details}

${ }^{1}$ South African Medical Research Council, 491 Ridge Road, Overport, Durban 4001, South Africa. ${ }^{2}$ Biosciences, CSIR, P.O.Box 395, Pretoria 0002, South Africa. ${ }^{3}$ Ethnobotany Unit, South African National Biodiversity Institute, School of Chemistry and Physics, University of KwaZulu-Natal, PO Box 52099, Berea Road 4007, Durban 4041, South Africa. ${ }^{4}$ South African Medical Research Council, P.O.Box19070, Tygerberg 7505, South Africa.

Received: 25 June 2012 Accepted: 28 August 2012

Published: 10 September 2012

\section{References}

1. Mouatcho JC, Hargreaves K, Koekemoer LL, Brooke BD, Oliver SV, Hunt RH, Coetzee M: Indoor collections of the Anopheles funestus group (Diptera: Culicidae) in sprayed houses in northern KwaZulu-Natal. South Afr Malar J 2007, 6:30.

2. World Health Organization: World malaria report WHO Global Malaria Programme; 2011.

3. National Department of Health: National Malaria Programme Performance Review Directorate: Malaria and other Vector-Borne Diseases; 2009.

4. National Department of Health: National Department of Health Strategic Plan; 2010:11-2012-13.

5. Lubombo Spatial Development Initiative: The LSDI Annual Report; 2009. http://www.malaria.org.za/Isdi/Reports/2009/LSDIMaputoAnnualReport2009. pdf.

6. Brooke BD, Kloke G, Hunt RH, Koekemoer LL, Temu EA, Taylor ME, Small G, Hemingway J, Coetzee M: Bioassay and biochemical analyses of insecticide resistance in southern African Anopheles funestus (Diptera: Culicidae). Bull Entomol Res 2001, 91:265-272.

7. Hargreaves K, Hunt RH, Brooke BD, Mthembu J, Weeto MM, Awolola TS, Coetzee M: Anopheles arabiensis and An. quadriannulatus resistance to DDT in South Africa. Med Vet Entomol 2003, 17:417-422.

8. Mouatcho JC, Munhenga G, Hargreaves K, Brooke BD, Coetzee M, Koekemoer LL: Pyrethroid resistance in a major African malaria vector Anopheles arabiensis from Mamfene, northern KwaZulu-Natal, South Africa. S Afr J Sci 2009, 105:127-131.

9. Walker $\mathrm{K}$ : Cost-comparison of DDT and alternative insecticides for malaria control. Med Vet Entomol 2000, 14:345-354.

10. Le Sueur D, Sharp BL: Temperature dependent variation in the head capsule width and wing length of Anopheles merus and implications for anopheline taxonomy. Med Vet Entomol 1991, 5:55-62.

11. Maharaj R: Life table characteristics of Anopheles arabiensis (Diptera: Culicidae) under simulated seasonal conditions. J Med Entomol 2003, 40:737-742

12. Bruce-Chwatt LJ: Essential malariology. London: William Heinemann Medical Books; 1985

13. Rajkumar S, Jebanesan A: Mosquitocidal activity of octacosane from Moschosma polystachyum L. (Lamiaceae). J Ethnopharmacol 2004, 90:87-89.

14. Markouk M, Bekkouche K, Larhsini M, Bousaid M, Lazrek HB, Jana M: Evaluation of some Moroccan medicinal plant extracts for larvicidal activity. J Ethnopharmacol 2000, 73:293-297.

15. Chariandy CM, Seaforth CE, Phelps RH, Pollard GV, Khambay BP: Screening of medicinal plants from Trinidad and Tobago for antimicrobial and insecticidal properties. J Ethnopharmacol 1999, 64:265-270.

16. Tona L, Ngimbi NP, Tsakala M, Mesia K, Cimanga K, Apers S, De Bruyne T, Pieters L, Totté J, Vlietinck AJ: Antimalarial activity of 20 crude extracts from nine African medicinal plants used in Kinshasa, Congo. J Ethnopharmacol 1999, 68:193-203.

17. Sathiyamoorthy P, Lugasi-Evgi H, Van Damme P, Abu-Rabia A, Gopas J, Pollack Y, Golan-Goldhirsh A: Larvicidal activity in desert plants of the 
Negev and Bedouin market plant products. Int J Pharmacog 1997, 35:265-273.

18. Thangam TS, Kathiresan K: Mosquito larvicidal activity of mangrove plant extracts and synergistic activity of R. apiculata with pyrethrum against Culex quinquefasciatus. Int J Pharmacog 1997, 35:69-71.

19. Geerts S, Van Blerk K, Triest L: Effect of Ambrosia maritima on Anopheles stephensi and Aedes aegypti. J Ethnopharmacol 1994, 42:7-11.

20. Evans DA, Raj RK: Extracts of Indian plants as mosquito larvicides. Indian J Med Res 1988, 88:38-41.

21. Dharmshaktu NS, Prabhakaran PK, Menon PK: Laboratory study on the mosquito larvicidal properties of leaf and seed extract of the plant Agave americana. J Trop Med Hyg 1987, 90:79-82.

22. Bagavan A, Rahuman AA: Evaluation of larvicidal activity of medicinal plant extracts against three mosquito vectors. Asian Pac J Trop Med 2011, 4:29-34.

23. Singh KV, Bansal SK: Larvicidal properties of perennial herb Solanum xanthocarpum against vectors of malaria and dengue/DHF. Curr Sci 2003, 84:749-751

24. Evans DA, Raj RK: Larvicidal efficacy of quassin against Culex quinquefasciatus. Indian J Med Res 1991, 93:324-327.

25. Govindarajan M: Larvicidal and repellent activities of Sida acuta Burm. F. (Family: Malvaceae) against three important vector mosquitoes. Asian Pac J Trop Med 2010, 3:691-695.

26. Francois G, van Looveren M, Timperman G, Chimanuka B, AkeAssi L, Holenz J, Bringmann G: Larvicidal activity of the naphthylisoquinoline alkaloid dioncophylline-A against the malaria vector Anopheles stephensi. J Ethnopharmacol 1996, 54:125-130.

27. Zarroug IMA, Nuggud AD, Bashir AK, Mageed AA: Evaluation of Sudanese plants. Int J Crude Drug Res 1988, 26:77-80.

28. Clarkson C, Maharaj VJ, Crouch NR, Grace OM, Pillay P, Matsabisa MG, Bhgawandin N, Smith PJ, Folb PI: In vitro antiplasmodial activity of medicinal plants native to or naturalised in South Africa. J Ethnopharmacol 2004, 92:177-191.

29. Maharaj R, Maharaj V, Newmarch M, Crouch NR, Bhagwandin N, Folb PI, Pillay P, Gayaram R: Evaluation of selected South African ethnomedicinal plants as mosquito repellents against the Anopheles arabiensis mosquito in a rodent model. Malar J 2010, 9:301.

30. Maharaj R, Maharaj V, Crouch NR, Bhagwandin N, Folb PI, Pillay P, Gayaram R: Screening for adulticidal bioactivity of South African plants against Anopheles arabiensis. Malar J 2011, 10:233.

31. World Health Organization: Manual on practical entomology. Geneva: WHO; 1975.

32. World Health Organization: Guidelines for laboratory and field testing of mosquito larvicides: WHO; 2005:13. CDS/WHOPES/GCDPP/.

33. Jang Y, Kim M, Ahn Y, Lee H: Larvicidal activity of Brazilian plants against Aedes aegypti and Culex pipiens pallens (Diptera: Culicidae). Agric Chem Biotechnol 2002, 45:131-134.

34. Arivoli S, Tennyson S: Studies on the mosquitocidal activity of Murraya koenigii (L.) Spreng (Rutaceae) leaf extracts against Aedes aegypti, Anopheles stephensi and Culex quinquefasciatus (Diptera: Culicidae). Asian J Exp Biol Sci 2011, 2:721-730.

35. Tiwary M, Naik SN, Tewary DK, Mittal PK, Yadav S: Chemical composition and larvicidal activities of the essential oil of Zanthoxylum armatum DC (Rutaceae) against three mosquito vectors. J Vector Borne Dis 2007, 44:198-204.

36. Orwa JA, Jondiko IJ, Minja RJ, Bekunda M: The use of Toddalia asiatica (L) Lam. (Rutaceae) in traditional medicine practice in East Africa. J Ethnopharmacol 2008, 115:257-262.

37. Borah R, Kalita MC, Kar A, Talukdar A: Larvicidal efficacy of Toddalia asiatica (Linn.) Lam against two mosquito vectors Aedes aegypti and Culex quinquefasciatus. Afr J Biotechnol 2010, 9:2527-2530.

38. Maharaj R: Global trends in insecticide resistance and impact on disease vector control measures. OAIP 2011, 3:27-33.

39. Das NG, Goswami D, Rabha B: Preliminary evaluation of mosquito larvicidal efficacy of plant extracts. J Vect Borne Dis 2007, 44:145-148.

doi:10.1186/1475-2875-11-320

Cite this article as: Maharaj et al: Screening of selected ethnomedicinal plants from South Africa for larvicidal activity against the mosquito Anopheles arabiensis. Malaria Journal 2012 11:320.

\section{Submit your next manuscript to BioMed Central and take full advantage of:}

- Convenient online submission

- Thorough peer review

- No space constraints or color figure charges

- Immediate publication on acceptance

- Inclusion in PubMed, CAS, Scopus and Google Scholar

- Research which is freely available for redistribution 